\title{
Original article (full paper) \\ Needs Satisfaction Effect on Exercise Emotional Response: A Serial Mediation Analysis with Motivational Regulations and Exercise Intensity
}

\author{
Diogo Santos Teixeira \\ Universidade Lusófona de Humanidades e Tecnologias, Lisboa, Portugal \\ António Labisa Palmeira \\ Universidade Lusófona de Humanidades e Tecnologias, Lisboa, Portugal \\ Universidade de Lisboa, Lisboa, Portugal
}

\begin{abstract}
Regarding psychological responses to exercise, this study aimed to analyze the mediating effects of motivational regulations and intensity in the association between basic psychological needs satisfaction and emotional responses. This was a cross-sectional study of 495 health club members $(M=40.50$ years; $S D=13.54)$; of these, 186 were women $(37.6 \%)$ and 309 men $(62.4 \%)$, with an average attendance of 2.61 sessions per week $(S D=1.29)$. Selfdetermination theory motivational regulations and basic psychological needs (BPN), perceived exercise intensity, and emotional response were measured. Serial mediation procedures were followed to test the interactions of variables. Models with autonomous regulations predicted positive emotional responses. As for the negative emotional response, the models with external regulation presented the highest predictions for negative activation. Results indicate that BPN satisfaction is associated with better emotional response, partially explained by autonomous regulations and perceived exercise intensity. In externally regulated individuals, perceived exercise intensity appears to be important to sustain a better emotional response.
\end{abstract}

Keywords: motivational regulation, basic psychological needs satisfaction, perceived exercise intensity, emotional response

\section{Introduction}

It is well known that physical exercise plays an important role in health promotion. However, research indicates that people seem to struggle to meet the international recommendations to achieve the warranted effects of exercise on health ${ }^{1}$. One of the most common contexts where people engage in exercise routines is health clubs, which represent one of fastest-growing markets in sport-related industries. Recent reports point that around 140 million club members worldwide are involved in some sort of activity in this context ${ }^{2}$. At this scale, research and understanding of the "how and why" people engage in exercise in this specific setting seems warranted, as a way to facilitate the attainment of public health recommendations for exercise.

Several mainstream theories have been used to study these problems and improve exercise adherence. Self-determination theory $(\mathrm{SDT})^{3}$ has been widely used throughout the years, continuously supported by evidence. The authors of SDT state that extrinsically motivated behaviors are distributed across four regulations: external regulation (behavior controlled by specific external contingencies); introjected regulation (doing a task to avoid internal pressure or to obtain social approval); identified regulation (recognition and acceptance of the value of a behavior); and integrated regulation (identification and integration of behaviors with others aspects of the self $)^{4}$. All of these regulations represent several degrees of behavior internalization, reflecting the transitioning of habits and requests into endorsed values and self-regulations ${ }^{4}$. SDT suggests that these may vary between controlled motivations (external and introjected regulations) and autonomous motivations (identified and integrated regulations), representing the results of the interaction with a particular environment, where a person has been less or more able to internalize and integrate the regulatory style of a particular activity 4,5 . This implies that intrinsic motivation and well-internalized extrinsic motivation (i.e., autonomous motives) and external and introjected regulation (i.e., controlled motives) determine the level of self-determined behavior for a particular task or activity, presenting important variables that improve the quality and facilitation of a particular behavior, as is the case of physical exercise.

To promote more autonomous motivations, the theory states that three basic psychological needs (BPN) should be satisfied: (1) competence, the feeling of being effective in producing desired outcomes and exercising one's capacities; (2) autonomy, the perception of being the originator of one's behavior and experiencing volition in action; and (3) relatedness, feelings of being respected, understood, and cared for by others (6). The satisfaction of these BPN has been shown to predict psychological well-being in all cultures (6) and in several contexts (e.g., exercise settings) ${ }^{7-9}$. Additionally, the satisfaction of BPN in general appears to promote a better emotional response ${ }^{10,11}$ and facilitates the internalization of motives that will influence the quality of motivation ${ }^{12}$. 
Exercise emotional response research has been revitalized in recent years ${ }^{13}$. Studies point to a relationship between exercise and emotional response, where high states of positive activation and low states of negative activation are associated with better exercise experiences, adherence, and general well-being ${ }^{14-16}$. Additionally, exercise intensity seems to play an important role in affective response. As seen in previous works, the emotional response in exercise differs accordingly with the possibility of self-selected intensity ${ }^{8,17,18}$ and the contrast of moderate vs. high intensity training ${ }^{18,19}$, indicating that participants, in accordance with their fitness levels, body composition, and type of activities, may experience different affective responses to a bout of exercise.

However, research regarding exercise intensity and its relationship with the interaction of SDT and well-being in health club contexts has been limited and underexplored. For example, Standage, Sebire, and Loney ${ }^{20}$ have developed a cross-sectional study with 55 participants involved in non-competitive swimming that objectively measures exercise behavior. Results indicated that autonomous exercise motivation positively predicted exercise bouts with three different intensities and durations, and no associations were found between controlled motivation and assessed bouts. However, the authors did not measure BPN satisfaction in their study. They suggest that the needs may act as facilitators of motivation and well-being, aiding in the internalization of a particular behavior and in the development of more autonomous motivations. Another study by Duncan, Hall, Wilson, Jenny ${ }^{14}$ analyzed exercise motivation and its relationship with some exercise behavior measures (e.g., selfreported exercise intensity) using 1,056 participants involved in several exercise and sport activities. The results stated that exercise intensity was not predicted by autonomous regulations or intrinsic motivation, contrasting with results from Standage et al. ${ }^{20}$. However, again the authors did not measure psychological needs and their relationship with the variables in study. As seen in Figure 1, social contextual factors (e.g., autonomy support) will influence needs satisfaction, which, in turn, affects the type of motivation and degree of internalization of the behavior, manifesting in cognitive, behavioral and affective outcomes.

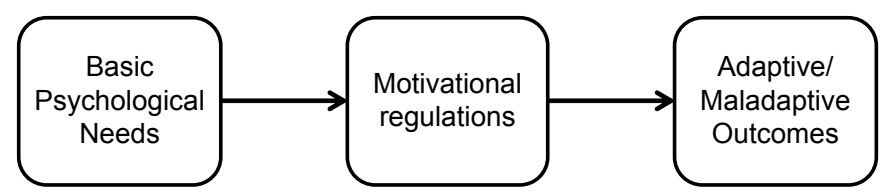

Figure 1. Main tenets of self-determination theory (Deci \& Ryan, 1985, 2000)

It is possible to accept that previous results concerning the influence of motivational regulations in exercise intensity could be influenced by the theory-supported antecedents such as BPN and context characteristics. Ryan, Patrick, Deci, and Williams ${ }^{21}$ have already suggested this, considering that the link from autonomous self-regulation to health outcomes was often indirect. Additionally, concerning context differences, health clubs have received less attention than other sport and exercise contexts in recent research based on the SDT framework (e.g., for a review please see $\mathrm{Ng}$, Ntoumanis, Thogersen-Ntoumani, Deci, Ryan, Duda, et al. ${ }^{7}$. The specific characteristics of the health club context (e.g., differences across available activities, number of exercise professionals and their work schedule in classes, specific exerciser interaction, etc.) should be recognized as important contextual variables that may be influencing needs satisfactions and, consequently, a whole range of variables that may influence the emotional experience of exercise.

Therefore, bearing in mind previous study limitations and having as reference the SDT tenets, the aim of this study was to analyze the mediating effects of motivational regulations and intensity in the association between BPN satisfaction and emotional response to exercise. For this purpose, serial mediation analysis procedures will be used. Several authors have sustained that the understanding of the mediating effects between variables provides important insight into the comprehension of their interactions and possible causal effects ${ }^{22}$. This analytical approach will allow for the test of the following hypothesis: Need satisfaction will lead to more autonomous regulations and influence adaptive outcomes (e.g., emotional response), partially explained by the influence of exercise intensity.

\section{Method}

\section{Participants}

The participants of this cross-sectional study were 495 health club members $(M=40.50$ years; $S D=13.54)$ recruited from several health clubs in Lisbon. Of these, 186 were women (37.6\%) and 309 men $(62.4 \%)$, with an average attendance of 2.61 sessions per week $(S D=1.29)$ and 9.28 years of practice $(S D=10.01)$, who completed a set of questionnaires evaluating the perceived intensity of their workouts and their BPN satisfaction, motivational regulations, and emotional response to exercise.

\section{Measures}

The questionnaire package contained instruments for the measurement of (a) the SDT variables (basic psychological needs and motivational regulations), (b) emotional response to exercise (positive and negative activation, psychological well-being, psychological distress, and fatigue), (c) ratings of perceived exertion (i.e., intensity), and (d) general sociodemographic variables.

The Portuguese version of the Psychological Need Satisfaction Scale $^{23}$ (Cronbach's $\alpha$ between 0.79 and 0.89 ) was used. This instrument allows the analysis of fitness club members needs satisfaction for autonomy (e.g., "I feel free to exercise in my own way"), competence (e.g., "I feel that I am able to complete exercises that are personally challenging"), and relatedness (e.g., "I feel attached to my exercise companions because they accept me for who I am"). This instrument was based on the original made by Wilson, Rogers, Rodgers, and Wild ${ }^{24}$, which was based on SDT theory and is widely used in exercise settings. It is composed of 18 items and uses a six-point Likert bipolar scale. For this study, we utilized a composite of the needs for the mediation analysis (i.e., [autonomy + competence + relatedness]/3), as previously done in some other studies, such as Hagger, Chatzisarantis, Harris ${ }^{25}$. 
The Portuguese version of the Behavioral Regulation in Exercise Questionnaire-2 (BREQ2 ${ }^{(26)}$ ), was used (Cronbach's $\alpha$ between 0.63 and 0.87 ). This instrument is a 19-item, self-report measure adapted from the original BREQ ${ }^{(27)}$. This instrument assesses exercise regulations based on the SDT framework. BREQ-2 includes five subscales assessing the following types of regulations: intrinsic [e.g., "I enjoy my exercise sessions" $(n=4)$ ], identified [e.g., "It's important to me to exercise regularly" $(n=4)$ ], introjected [e.g., "I feel guilty when I don't exercise" $(\mathrm{n}=3)$ ], and external [e.g., "I feel under pressure from my family/friends to exercise" $(n=4)]$; and also amotivation [e.g., "I don't see why I should have to exercise;"(n=4)]. A five-point scale ranging from 0 (not true for me) to 4 (very true for $m e$ ) were used. Reliability studies show support for the application of this instrument in this context ${ }^{28}$.

We created a composite of autonomous regulations (i.e., [identified + intrinsic] $/ 2$; Cronbach's $\alpha=0.70$ ) for the mediation analysis. Some suppression effects of these variables, when analyzed independently, were previously reported to be demonstrated by mixed interpretations in correlation and mediation analysis that may indicate some buffering effects of one autonomous regulation over others ${ }^{29-31}$. Additionally, the similarities between constructs justified the choice of creating the composite variable. Regarding controlled regulations (external and introjected), the variables were treated individually due to their dissimilar constructs and potential for separately influencing behavior and well-being ${ }^{31,32}$. To facilitate results interpretation, all motivational regulations will be presented in the correlation analysis.

The Portuguese version of Subjective Exercise Experiences Scale (SEES; Palmeira ${ }^{33}$; Cronbach's $\alpha$ between 0.79 and 0.88 ) is a brief, 12-item scale assessing positive well-being (PWB; four items; e.g., great, strong), psychological distress (PD; four items; e.g., crummy, awful), and fatigue (four items; e.g., tired, fatigued) based on McCauley and Courneya's ${ }^{34}$ original instrument. This instrument appears to be sensitive to exercise intensity and is supported in young and middle-aged adults ${ }^{34,35}$.

The Portuguese version of the Positive And Negative Affects Scale (PANAS; Cronbach's $\alpha$ ranging from 0.85 to 0.90 ) by Galinha, Ribeiro ${ }^{36}$ uses a five-point scale to assess the positive and negative affect the participants felt in their activities. The instrument consists of 10 items that tap positive affect (i.e., inspired, alert, excited, enthusiastic, and determined) and 10 for negative affect (i.e., distressed, scared, nervous, upset, and afraid). This instrument has been widely used in exercise settings ${ }^{13}$ and has shown acceptable internal consistencies and test-retest reliability ${ }^{37,38}$. We will use the authors suggested name change - Positive and Negative Activation (PA and NA) Scale - to more clearly indicate that the dimensions refer to something other than pleasure and displeasure and are defined only by their high-arousal poles ${ }^{13,39}$.

Perceived intensity was assessed using a modified version of the rating of perceived exertion scale ${ }^{40}$. This instrument presented the stem "Generally in your exercise, the intensity is..." with a scale ranging between 0 (nothing) to 11 (maximum possible). This instrument has been widely used in exercise settings and its validity and reliability is well-established ${ }^{41}$.

\section{Procedures}

The questionnaires were available at the reception desk of health clubs. Users were asked to fill out questionnaires that would allow researchers to study factors associated with the quality of their exercise experience. The participation was voluntary and the instruments were available for a pre-defined period (informed consent about participation was available at the beginning of the questionnaires). We collected the responses and gathered them into a single database. The University Scientific Board approved this study.

\section{Data analysis}

Descriptive statistics, partial correlations and independent $t$ tests were calculated using IBM SPSS Statistics, version 21.0. Data analysis required testing the mediating effects (i.e., indirect effects) of BPN satisfaction on emotional response to exercise through serial mediators (motivational regulations and exerciseperceived intensity). The most widely used method for this type of analysis is structural equation modeling (SEM), which can be used for testing latent variables. After database preparation, we verified that the sample in our study was not large enough for the number of parameters estimated in the SEM approach. Therefore, we used Baron and Kenny's ${ }^{42}$ causal steps procedure and bootstrapping method as they are supported by several authors for testing the significance of indirect effects ${ }^{43,44}$. Bootstrapping procedures have been considered more efficient than the normal theory approach due to more accurate type I errors rates and are more powerful for detecting indirect effects in smaller samples ${ }^{44}$.

We used the PROCESS macro for SPSS ${ }^{45}$ for serial multiple mediation. This procedure allows the study of direct and indirect effects of $X$ on $Y$ while modeling a process in which $X$ causes $M 1$, which, in turn, causes $M 2$, concluding with $Y$ as outcome ${ }^{46}$. We have used the macro's model 6, which defines this logical, causal sequence with two mediators (Figure 2). This model allows the control of the indirect effect of individual mediators, while controlling for other variables. Bias-corrected bootstrapped point estimates for the indirect effects of the independent variable on the dependent were calculated, together with standard errors and $95 \%$ confidence intervals. The indirect effect is significant (at alpha $=.05$ ) if its $95 \%$ confidence interval does not encompass zero. The Preacher and Hayes macros also provide regression coefficients for the causal steps of the specific indirect effects.

For this specific study, the procedure provided the direct effect (c') of the independent variable (X) (i.e., BPN satisfaction) on the dependent variable (Y) (i.e., emotional response) and the indirect effect through individual variables (M1: motivational regulations; $\mathrm{a}_{1} \mathrm{x}_{\mathrm{1}}$ and $\mathrm{M} 2$ : exercise-perceived intensity; $\mathrm{a}_{2} \mathrm{x}_{2}$ ) and global influence of mediators (M1 + M2; $\mathrm{a}_{1} \mathrm{x} \mathrm{d}_{21} \mathrm{x}_{2}$ ). The total effect is given as result of the direct effect and all of the mediator's indirect effects. Bootstrapping with 5000 samples was used with bias-corrected and accelerated intervals to make inferences. 


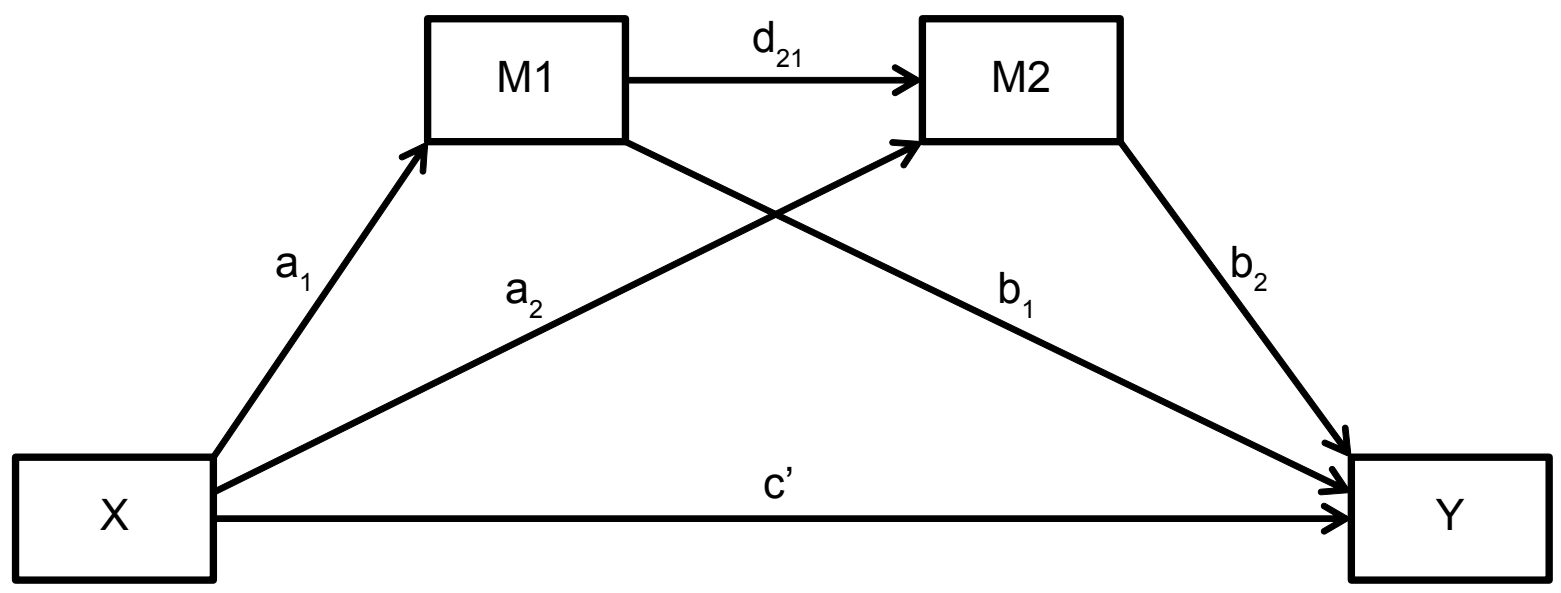

Figure 2. Statistical diagram of multiple mediation model 6 (Preacher \& Hayes, 2008)

\section{Results}

Differences between the genders were found for intensity $(t(493)=5.56, p<.001), \mathrm{PA}(t(493)=2.62, p=0.009), \mathrm{PWB}$ $(t(493)=2.28, p=0.02)$ and fatigue $(t(493)=3.21, p=0.001)$. Thus, gender was used as a control variable in the correlational and mediation analysis.

Table 1 shows that BPN is positively associated with autonomous regulations, exercise intensity, $\mathrm{PA}$, and PWB, and negatively associated with external regulation, NA, and PD. Additionally, autonomous regulations present positive associations with intensity, PA, and PWB, and a negative association with PD. Exercise intensity also indicates positive associations with PA, PWB, and fatigue. For introjected regulation, positive associations were found with external and identified regulations, justifying our decision to perform separate serial mediation analysis with the two controlled motivations.

Table 1. Mean, standard deviation and correlation analysis of intensity, basic psychological needs, motivational regulations and emotional response

\begin{tabular}{|c|c|c|c|c|c|c|c|c|c|c|c|c|c|c|c|c|c|}
\hline & $\boldsymbol{\alpha}$ & $\mathbf{M}$ & SD & 1 & 2 & 3 & 4 & 5 & 6 & 7 & 8 & 9 & 10 & 11 & 12 & 13 & 14 \\
\hline Intensity & & 5.54 & 2.09 & & & & & & & & & & & & & & \\
\hline Competence & 0.87 & 30.25 & 4.80 & $0.31 * * *$ & & & & & & & & & & & & & \\
\hline Autonomy & 0.88 & 27.78 & 6.84 & $0.17 * * *$ & $0.33^{* * *}$ & & & & & & & & & & & & \\
\hline Relatedness & 0.90 & 25.32 & 7.07 & $0.09^{*}$ & $0.40^{* * *}$ & $0.20 * * *$ & & & & & & & & & & & \\
\hline BPN & 0.88 & 27.78 & 4.56 & $0.24 * * *$ & $0.72^{* * *}$ & $0.72 * * *$ & $0.75^{* * *}$ & & & & & & & & & & \\
\hline $\begin{array}{l}\text { External regula- } \\
\text { tion }\end{array}$ & 0.79 & 1.36 & 2.45 & $-0.11^{*}$ & $-0.23 * * *$ & $-0.12 * *$ & 0.01 & $-0.14 * *$ & & & & & & & & & \\
\hline $\begin{array}{l}\text { Introjected } \\
\text { regulation }\end{array}$ & 0.70 & 4.43 & 3.19 & 0.04 & -0.01 & 0.01 & 0.08 & 0.04 & $0.30 * * *$ & & & & & & & & \\
\hline $\begin{array}{l}\text { Identified regu- } \\
\text { lation }\end{array}$ & 0.64 & 12.66 & 2.44 & $0.21 * * *$ & $0.29^{* * *}$ & $0.12 * *$ & $0.19 * * *$ & $0.26^{* * *}$ & -0.08 & $0.31 * * *$ & & & & & & & \\
\hline $\begin{array}{l}\text { Intrinsic regula- } \\
\text { tion }\end{array}$ & 0.71 & 13.73 & 2.32 & $0.19 * * *$ & $0.39 * * *$ & $0.17 * * *$ & $0.25 * * *$ & $0.35^{* * *}$ & $-0.29 * * *$ & 0.02 & $0.50 * * *$ & & & & & & \\
\hline $\begin{array}{l}\text { Autonomous } \\
\text { regulation }\end{array}$ & 0.70 & 13.20 & 2.06 & $0.23 * * *$ & $0.39^{* * *}$ & $0.17^{* * *}$ & $0.25^{* * *}$ & $0.35^{* * *}$ & $-0.20 * * *$ & $0.19^{* * *}$ & $0.87^{* * *}$ & $0.86^{* * *}$ & & & & & \\
\hline $\begin{array}{l}\text { Positive activa- } \\
\text { tion }\end{array}$ & 0.87 & 36.78 & 6.09 & $0.30 * * *$ & $0.40^{* * *}$ & $0.13 * *$ & $0.16^{* *}$ & $0.29 * * *$ & $-0.09 *$ & $0.12 *$ & $0.22 * * *$ & $0.34 * * *$ & $0.32 * * *$ & & & & \\
\hline $\begin{array}{l}\text { Negative activa- } \\
\text { tion }\end{array}$ & 0.78 & 12.84 & 3.91 & 0.16 & $-0.18 * * *$ & $-0.11 *$ & -0.07 & $-0.15 * *$ & $0.27 * * *$ & $0.19^{* * *}$ & 0.01 & $-0.13 * *$ & -0.07 & $-0.16^{* * *}$ & & & \\
\hline $\begin{array}{l}\text { Psychological } \\
\text { well-being }\end{array}$ & 0.78 & 21.49 & 4.05 & $0.27 * * *$ & $0.36^{* * *}$ & $0.19^{* * *}$ & $0.16^{* * *}$ & $0.30^{* * *}$ & $-0.12 * *$ & $0.17 * * *$ & $0.27 * * *$ & $0.42 * * *$ & $0.40^{* * *}$ & $0.49 * * *$ & $-0.09 *$ & & \\
\hline $\begin{array}{l}\text { Psychological } \\
\text { distress }\end{array}$ & 0.76 & 4.82 & 1.97 & -0.05 & $-0.23 * * *$ & $-0.13 * *$ & -0.05 & $-0.17 * * *$ & $0.37 * * *$ & $0.11 * *$ & -0.09 & $-0.15^{* *}$ & $-0.14 * *$ & -0.08 & $0.27 * * *$ & $-0.22 * * *$ & \\
\hline Fatigue & 0.87 & 14.21 & 6.04 & $0.21 * * *$ & 0.05 & 0.04 & -0.05 & 0.01 & $0.12 * *$ & $0.11^{* *}$ & 0.06 & -0.01 & 0.03 & 0.03 & $0.13^{* *}$ & 0.08 & $0.11^{*}$ \\
\hline
\end{tabular}

Note. ${ }^{*} \mathrm{p}<.05 ; * * \mathrm{p}<.01 ; * * \mathrm{p}<.001$ 
Table 2. Mediation analysis of basic psychological needs, motivational regulations, exercise intensity and emotional response

\begin{tabular}{|c|c|c|c|c|c|c|c|c|c|c|c|c|c|c|c|c|c|c|c|c|}
\hline \multirow[t]{2}{*}{ Direct effect of IV on DV } & \multicolumn{4}{|c|}{ Positive activation } & \multicolumn{4}{|c|}{ Negative activation } & \multicolumn{4}{|c|}{ Psychological well-being } & \multicolumn{4}{|c|}{ Psychological distress } & \multicolumn{4}{|c|}{ Fatigue } \\
\hline & Beta & SE & $\mathbf{t}$ & $p$ & Beta & SE & $\mathbf{t}$ & $p$ & Beta & SE & $\mathbf{t}$ & $p$ & Beta & SE & $\mathbf{t}$ & $p$ & Beta & SE & $\mathbf{t}$ & $p$ \\
\hline $\begin{array}{l}\text { BPN (Autonomous regula- } \\
\text { tion models) }\end{array}$ & 0.21 & 0.06 & 3.51 & $<.001$ & -0.13 & 0.04 & -3.25 & 0.001 & 0.14 & 0.04 & 3.62 & $<.001$ & -0.06 & 0.02 & -2.94 & 0.003 & -0.05 & 0.06 & -0.83 & 0.406 \\
\hline $\begin{array}{l}\text { BPN (External regulation } \\
\text { models) }\end{array}$ & 0.29 & 0.06 & 5.07 & $<.001$ & -0.12 & 0.04 & -3.03 & 0.003 & 0.22 & 0.04 & 5.68 & $<.001$ & -0.05 & 0.02 & -2.95 & 0.003 & -0.03 & 0.06 & -0.55 & 0.58 \\
\hline $\begin{array}{l}\text { BPN (Introjected regulation } \\
\text { models) }\end{array}$ & 0.29 & 0.06 & 5.15 & $<.001$ & -0.15 & 0.04 & -3.83 & $<.001$ & 0.22 & 0.04 & 5.83 & $<.001$ & -0.07 & 0.02 & -3.79 & $<.001$ & -0.06 & 0.06 & -0.99 & 0.322 \\
\hline \multirow{2}{*}{ Test for indirect effects } & \multicolumn{4}{|c|}{ Positive activation } & \multicolumn{4}{|c|}{ Negative activation } & \multicolumn{4}{|c|}{$\begin{array}{l}\text { Psychological well- } \\
\text { being }\end{array}$} & \multicolumn{4}{|c|}{ Psychological distress } & \multicolumn{4}{|c|}{ Fatigue } \\
\hline & Beta & \multicolumn{3}{|c|}{$\mathrm{Bc} 95 \% \mathrm{CI}$} & Beta & \multicolumn{3}{|c|}{$\mathrm{Bc} 95 \% \mathrm{CI}$} & Beta & \multicolumn{3}{|c|}{$\mathrm{Bc} 95 \% \mathrm{CI}$} & Beta & \multicolumn{3}{|c|}{$\mathrm{Bc} 95 \% \mathrm{CI}$} & Beta & \multicolumn{3}{|c|}{$\mathrm{Bc} 95 \% \mathrm{CI}$} \\
\hline BPN total as IV & & Lower & \multicolumn{2}{|c|}{ Upper } & & Lower & \multicolumn{2}{|c|}{ Upper } & & Lower & \multicolumn{2}{|c|}{ Upper } & & Lower & \multicolumn{2}{|c|}{ Upper } & & Lower & \multicolumn{2}{|c|}{ Upper } \\
\hline Total indirect effect & $0.17 *$ & 0.11 & \multicolumn{2}{|c|}{0.24} & 0.01 & -0.03 & \multicolumn{2}{|c|}{0.04} & $0.13 *$ & 0.09 & \multicolumn{2}{|c|}{0.18} & -0.01 & -0.04 & \multicolumn{2}{|c|}{0.01} & $0.07 *$ & 0.01 & \multicolumn{2}{|c|}{0.13} \\
\hline Autonomous regulation & $0.10 *$ & 0.06 & & .16 & -0.01 & -0.04 & & .02 & $0.10 *$ & 0.06 & & .14 & -0.01 & -0.04 & & .01 & -0.01 & -0.05 & & 05 \\
\hline $\begin{array}{l}\text { Autonomous regulation + } \\
\text { intensity }\end{array}$ & $0.02 *$ & 0.01 & & .03 & 0.01 & -0.01 & & .01 & $0.01 *$ & 0.01 & & .02 & 0.01 & -0.01 & & .01 & $0.02 *$ & 0.01 & & 04 \\
\hline Intensity & $0.05 *$ & 0.02 & & 0.1 & 0.01 & -0.01 & & .03 & $0.03 *$ & 0.01 & & .05 & 0.01 & -0.01 & & .01 & $0.05^{*}$ & 0.02 & & .1 \\
\hline r2 adj for DV model & 18.9 & $99 \%$ & & $\begin{array}{l}\text {, 490) } \\
8.72, \\
5,001 \\
\end{array}$ & 3.20 & & $\begin{array}{r}F \\
490) \\
p=0 \\
\end{array}$ & $\begin{array}{l}(4, \\
=4.05 \\
0.003\end{array}$ & $22.0^{7}$ & $7 \%$ & $\begin{array}{r}F \\
490)= \\
p<\end{array}$ & $\begin{array}{l}\mathrm{F}(4, \\
=34.70, \\
.001\end{array}$ & 4.17 & $7 \%$ & $\begin{array}{r}F( \\
490)= \\
p<.\end{array}$ & $\begin{array}{l}(4, \\
=34.70, \\
.001\end{array}$ & 6.38 & $8 \%$ & $\begin{array}{r}\mathrm{F}( \\
490)= \\
\mathrm{p}<.0\end{array}$ & $\begin{array}{l}4, \\
=8.35, \\
001 \\
\end{array}$ \\
\hline Total indirect effect & $0.09 *$ & 0.04 & & .14 & -0.01 & -0.05 & & .01 & $0.05 *$ & 0.03 & & .08 & $-0.02 *$ & -0.04 & & .01 & $0.05^{*}$ & 0.01 & & .1 \\
\hline External regulation & 0.01 & -0.01 & & .03 & $-0.03 *$ & -0.06 & & 0.01 & 0.01 & -0.01 & & .02 & $-0.02 *$ & -0.04 & & .01 & $-0.03 *$ & -0.06 & & .01 \\
\hline $\begin{array}{l}\text { External regulation + } \\
\text { intensity }\end{array}$ & $0.01 *$ & 0.01 & & .01 & $0.01 *$ & 0.01 & & .01 & $0.01 *$ & 0.01 & & .01 & 0.01 & -0.01 & & .01 & $0.01 *$ & 0.01 & & 01 \\
\hline Intensity & $0.08 *$ & 0.04 & & .13 & 0.02 & -0.01 & & .04 & $0.04 *$ & 0.02 & & .07 & 0.01 & -0.01 & & .01 & $0.07 *$ & 0.04 & & 12 \\
\hline r2 adj for $D V$ model & 15.1 & $11 \%$ & & $\begin{array}{l}\text {, } 490) \\
21.81, \\
<001 \\
\end{array}$ & 9.78 & & $\begin{array}{r}\mathrm{F} \\
490)= \\
\mathrm{p}<\end{array}$ & $\begin{array}{l}(4, \\
=13.27, \\
.001\end{array}$ & 14,38 & $8 \%$ & $\begin{array}{r}F \\
490)= \\
p< \\
\end{array}$ & $\begin{array}{l}\mathrm{F}(4, \\
=20.58, \\
.001\end{array}$ & 15.97 & $7 \%$ & $\begin{array}{r}F( \\
490)= \\
p<.\end{array}$ & $\begin{array}{l}(4, \\
=23.29, \\
.001\end{array}$ & 8,26 & $6 \%$ & $\begin{array}{r}\mathrm{F}( \\
490)=1 \\
\mathrm{p}<.0\end{array}$ & \begin{tabular}{l|}
4, \\
$=11.03$, \\
001 \\
\end{tabular} \\
\hline Total indirect effect & $0.08 *$ & 0.04 & & .14 & 0.02 & -0.01 & & .05 & $0.05 *$ & 0.02 & & .08 & 0.01 & -0.01 & & .01 & $0.07 *$ & 0.04 & & 12 \\
\hline Introjected regulation & 0.01 & -0.01 & & .02 & 0.01 & -0.01 & & .02 & 0.01 & -0.01 & & .02 & 0.01 & -0.01 & & .01 & 0.01 & -0.01 & & 02 \\
\hline $\begin{array}{l}\text { Introjected regulation + } \\
\text { intensity }\end{array}$ & 0.01 & -0.01 & & .01 & $0.01 *$ & 0.01 & & .01 & $0.01-$ & -0.01 & & 0.01 & 0.01 & -0.01 & & .01 & 0.01 & -0.01 & & 01 \\
\hline Intensity & $0.08 *$ & 0.04 & & .13 & 0.01 & -0.01 & & .03 & $0.04 *$ & 0.02 & & .07 & -0.01 & -0.01 & & .01 & $0.07 *$ & 0.03 & & 12 \\
\hline r2 adj for DV model & 15.9 & $91 \%$ & $\begin{array}{l}\mathrm{F}(4, \\
=2 \\
\mathrm{p}<\end{array}$ & $\begin{array}{l}, 490) \\
23.17 \\
<001 \\
\end{array}$ & 7.05 & & $\begin{array}{r}F \\
490)= \\
\mathrm{p}<\end{array}$ & $\begin{array}{l}(4, \\
=9.29 . \\
001\end{array}$ & 16.32 & $2 \%$ & $\begin{array}{r}F \\
490)= \\
p<\end{array}$ & $\begin{array}{l}F(4, \\
=23.59 . \\
<.001\end{array}$ & 4.90 & $0 \%$ & $\begin{array}{r}F( \\
490)= \\
p<.\end{array}$ & $\begin{array}{l}(4, \\
=6.32 . \\
001\end{array}$ & 7.37 & $7 \%$ & $\begin{array}{r}F( \\
490)= \\
p<.0\end{array}$ & $\begin{array}{l}(4, \\
=9.75 \\
001\end{array}$ \\
\hline
\end{tabular}

Note. ${ }^{*}$ The $95 \% \mathrm{CI}$ of the Bias and Corrected and Accelerated estimates indicate a significant indirect effect

Table 2 presents the mediating effect of motivational regulations and intensity in the relationship between BPN satisfaction and emotional response to exercise (PA-NA and PWB-PDfatigue). For the mediation analysis, the independent variable (BPN), dependent variable (emotional response), and Mediator 2 (intensity) were used in all analyses. The Mediator 1 comprised three separate analyses for the three constructs (autonomous regulations, introjected regulation, and external regulation), thus three serial mediation models were calculated.

Analysis shows that BPN is positively associated with PA and PWB (in all models) and negatively associated with NA and PD (again, in all models). Autonomous regulations appear to partially explain the relationship between BPN and emotional response with emphasis on the positive response. When this mediator is replaced by external regulation or introjected regulation, this mediating effect diminishes, as seen in direct effect differences between models. External regulation appears to be explaining, albeit to a lesser degree, the scores in NA and PD that may be affecting the negative emotional response. In all models, intensity partially explains the BPN-emotional response relationship with emphasis on the external and introjected regulations models.

The models with the autonomous regulations as the first mediator predicted the positive emotional response (PA, 18.99\%, $p<.001$ and PWB, 22.07, $p<.001)$. Conversely, the analysis with external and introjected regulations as the first mediator showed a decrease in positive emotional outcome predictions. As for the negative emotional response, the models with external regulation in the serial mediation presented the highest predictions for NA $(9.78 \%, p<.001)$ and PD $(15.97 \%, p<.001)$. Fatigue presented similar prediction scores, despite the type of motivational regulation.

\section{Discussion}

This study aimed to analyze the mediating effects of motivational regulations and exercise intensity in the association between BPN satisfaction and emotional response to exercise. 
In all mediation analysis, the BPN satisfaction stands out as one important predictor of good emotional response to exercise. The BPN presented positive associations with PA and PWB and negative associations with NA and PD, in line with the partial correlations. These results have been supported in previous findings in similar contexts, enhancing the importance of the development of needs-supportive contexts by exercise professionals ${ }^{7,11,12,47}$, and are in line with SDT predictions related to BPN satisfaction and adaptive outcomes ${ }^{6,8,9}$. Additionally, several studies in similar contexts suggest that BPN satisfaction (despite differences in each one of the needs) fosters self-determination, which has been reported to be associated with well-being, better adaptive outcomes, and exercise adherence ${ }^{7,48,49}$.

Analysis also showed that there were mediating effects of motivational regulations and exercise intensity interacting in emotional outcomes. When autonomous regulation was the first mediator, significant indirect effects appear associated with PA and PWB, surpassing the indirect effect presented by exercise-perceived intensity. However, when the mediators were external or introjected regulations, the total indirect effect on the emotional outcome diminishes, reflecting a stronger direct effect of the BPN. Contrastingly, controlled regulations did not

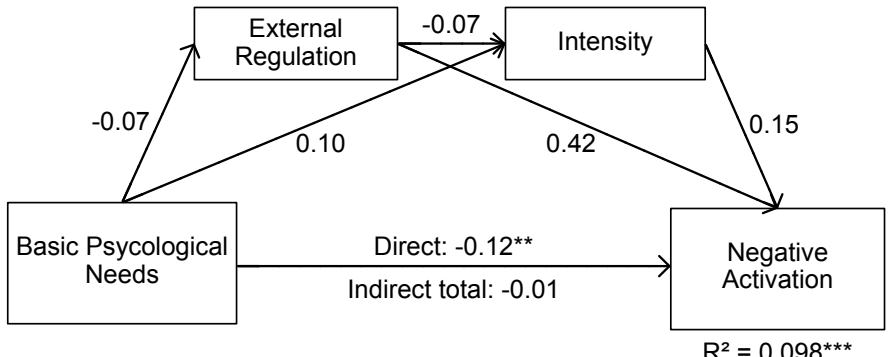

influence positive emotional response as did the autonomous regulations models, and interacted negatively with NA/PD in the external regulation model. Considering that correlation analysis presented positive associations between external regulation and $\mathrm{NA} / \mathrm{PD}$, the mediation analysis suggests that this regulation was partially counteracted by needs satisfaction. Looking at $\mathrm{a}_{1}$ and $\mathrm{b}_{1}$ paths, the positive associations between external regulation and NA/PD still exists, but they are weakened by the negative association between BPN and external regulation (Figure 3). Taking into account previous indications regarding the influence of motivational regulations in several exercise outcomes, it seems that autonomous regulations presented by exercisers may be one explanatory mechanism for how better emotional responses are experienced ${ }^{7,11}$. Interestingly, and in contrast to the hypothesis according to SDT tenets, controlled regulations did not present a significant detrimental effect on emotional response in the mediation analysis. The controlled forms of regulations have received some contradictory evidence in this regard, particularly due to a possible double-sided facet of the introjected regulation ${ }^{50}$. Despite this, from this study it seems that BPN satisfaction has a buffer effect in controlled regulations, which may justify these results.

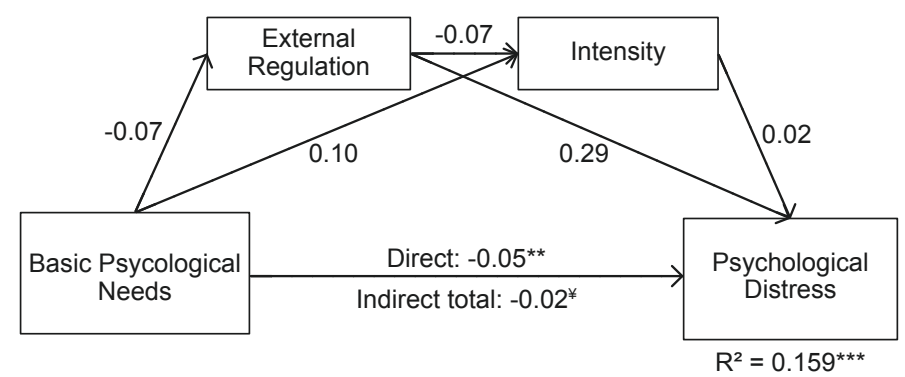

Note. ${ }^{* *} \mathrm{p}<.01 ; * * * \mathrm{p}<.001 ; ¥$ the $95 \% \mathrm{CI}$ of the Bias and Corrected and Accelerated estimates indicate a significant indirect effect

Figure 3. Serial mediation models for basic psychological needs, external regulations and negative emotional response

Regarding exercise intensity, partial correlations shows positive associations with PA/PWB and autonomous regulations and negative associations with external regulation. In the mediation models, intensity appears to be a possible mechanism explaining the relationship of BPN to emotional response, particularly in the controlled regulation models. As seen in Table 2, intensity accounts for almost all of the indirect effects in external and introjected models, standing out in comparison to the autonomous regulation models. This may suggest that people engaging in these types of activities through controlled regulations may experience exercise intensity that mediates their BPN satisfaction and emotional response. Some studies have supported the importance of intensity in emotional response ${ }^{8,17-19}$, particularly when the exercise is under the ventilatory or lactate threshold ${ }^{51}$. Exercise intensity in our sample $(M=5.51$; lower range of strong intensity) seems to be adjusted to these concerns and may partially ensure the emotional outcome.

Therefore, one of the novelties brought by this study concerns the importance of perceived exercise intensity in the relationship between exercise prescription and emotional response in less self-determined individuals. If, through better use of self-selected exercise intensity tools (e.g., Felling Scale), professionals could improve exercise emotional control and response, an increase in people's adherence to exercise should be expected ${ }^{52}$. Combined with need-supportive environments adjusted to individual's characteristics, some strong tools may be available to professionals in the future to help them adjust their programs and interventions.

These results bring additional standpoints to exercise professionals in health club settings that, notwithstanding, should be interpreted with some caution. One study limitation concerns the self-reported intensity measure. Despite validity in similar contexts, an objective measure should be used in the future to provide more reliable data. For general sport activities, the analysis of BPN satisfaction has evidenced SDT assumptions, but generalization should be done with caution due to the high diversity of contexts, involved individuals, and activities developed $^{53}$. It should be plausible that an exerciser who attends only group classes would get different needs satisfaction than another who undertakes only individual activities, or even someone that trains according to different schedules every week and, therefore, is constantly interacting with different professionals and exercisers (i.e., the need for autonomy may be diminished in a choreographed class or the relatedness need may be improved 
due to exercisers' interactions). In this study, we did not account for these particularities, but they should provide some guidelines to future research in this context. Additionally, this particular exercise setting contrasts with the sport or physical education contexts in one additional important factor as, throughout the sessions of training, the exercise professional may be someone else who provides different teaching and motivational styles ${ }^{53}$. This should be a focus for future studies, where professionals' teaching and motivational styles could be measured and studied in order to better understand how they individually influence BPN satisfaction and the development of self-determination behavior. As a last limitation and recommendation, needs frustration should be considered an important variable ${ }^{54}$. To fully understand the relationship between BPN and psychological or behavioral outcome, not only is it important to control satisfaction vs. dissatisfaction but the possible (and somehow expected) active needs frustration resulting from context diversity should be better understood.

In conclusion, serial mediation models indicate that BPN satisfaction is associated with better emotional response in health club exercisers. This is partially explained by autonomous regulations and perceived exercise intensity. In externally regulated individuals, perceived exercise intensity appears to be important to sustain a better emotional response to exercise.

\section{References}

1. Department of Health and Human Services. Physical activity guidelines advisory Committee report. Washington DC, U.S. Department of Health and Human Services, 2008.

2. IRSHA. The 2014 IHRSA Global Report. Retrieved October, 16, 2014. Avaiable from http://www.ihrsa.org/blog/2014/5/27/2014ihrsa-global-report-is-out-in-pdf.htm

3. Deci EL, Ryan RM. Intrinsic motivation and self-determination in human behavior. New York, Plenum, 1985.

4. Deci EL, Ryan RM. The "What" and "Why" of Goal Pursuits: Human Needs and the Self-Determination of Behavior. Psychol Inq. 2000; 11: 227-268.

5. Vallerand RJ. Toward a hierarchical model of intrinsic and extrinsic motivation. In: Advances in exp social psychol. San Diego, Academic, 1997.

6. Deci EL, Ryan RM. Self-determination theory: a macrotheory of human motivation, development, and health. Canada Psychol. 2008; 49: 182-185.

7. Ng. JYY, Ntoumanis N, Thogersen-Ntoumani C, Deci EL, Ryan RM, Duda JL, Williams GC. Self-Determination Theory Applied to Health Contexts: A Meta-Analysis. Perspect Psychol Sci. 2012; 7: 325-340.

8. Schneider ML, Kwan BM. Psychological need satisfaction, intrinsic motivation and affective response to exercise in adolescents. Psychol Sport Exerc. 2013; 14: 776-785.

9. Wilson P, Mack D, Blanchard C, Gray C. The role of perceived psychological need satisfaction in exercise-related affect. Hellenic J Psychol. 2009; 6: 183-206.

10. Gunnell KE, Crocker PRE, Mack DE, Wilson PM, Zumbo BD. Goal contents, motivation, psychological need satisfaction, well-being and physical activity: A test of self-determination theory over 6 months. Psychol Sport Exerc. 2014; 15: 19-29.

11. Teixeira PJ, Carraça EV, Markland D, Silva MN, Ryan RM. Exercise, physical activity, and self-determination theory: A systematic review. Int J Behav Nutr Phys Act. 2012; 9: 78.

12. Ryan RM, Deci EL. Self-determination theory and the facilitation of intrinsic motivation, social development, and well-being. Am Psychol. 2000; 55: 68-78.

13. Ekkekakis P, Hargreaves E, Parfitt G. Invited Guest Editorial: Envisioning the next fifty years of research on the exercise-affect relationship. Psychol Sport Exerc. 2013; 14: 751-758.

14. Duncan LR, Hall CR, Wilson PM, Jenny O. Exercise motivation: a cross-sectional analysis examining its relationships with frequency, intensity, and duration of exercise. Int J Behav Nutr Phys Act. 2010; 7.

15. Ekkekakis P, Thome J, Petruzzello SJ, Hall EE. The Preference for and Tolerance of the Intensity of Exercise Questionnaire: a psychometric evaluation among college women. J Sports Scienc. 2008; 26: 499-510.

16. Garcia D, Archer T, Moradi S, Andersson-Arntén A-C. Exercise Frequency, High Activation Positive Affect, and Psychological Well-Being: Beyond Age, Gender, and Occupation. Psychol. 2012; 3: 328-336.

17. Rose E, Parfitt G. Pleasant for some and unpleasant for others: a protocol analysis of the cognitive factors that influence affective responses to exercise. Int J Behav Nutr Phys Act. 2010; 7: 15.

18. Williams DM, Raynor HA. Disentangling the effects of choice and intensity on affective response to and preference for self-selectedversus imposed-intensity physical activity. Psychol Sport Exerc. 2013; 14: 767-775.

19. Lind E, Ekkekakis P, Vazou S. The affective impact of exercise intensity that slightly exceeds the preferred level: "Pain" for no added "gain". J Health Psychol. 2008; 13: 464-468.

20. Standage M, Sebire S, Loney T. Does exercise motivation predict engagement in objectively assessed bouts of moderate-intensity exercise? A self-determination theory perspective. J Sport Exerc Psychol. 2008; 30: 337-352.

21. Ryan RM, Patrick H, Deci EL, Williams GC. Facilitating health behaviour change and its maintenance: Interventions based on self-determination theory. Europ Health Psychol. 2008; 10: 2-5.

22. Shrout PE, Bolger N. Mediation in experimental and nonexperimental studies: New procedures and recommendations. Psychol Meth. 2002; 7: 422-445.

23. Palmeira AL. Validação preliminar da escala da satisfação das necessidades psicológicas básicas no exercício. XIII Jornadas da Sociedade Portuguesa de Psicologia do Desporto, Lisboa, Portugal, 2012.

24. Wilson PM, Rogers WT, Rodgers WM, Wild TC. The Psychological Need Satisfaction in Exercise Scale. Wild. 2006: 231-251.

25. Hagger MS, Chatzisarantis NLD, Harris J. From psychological need satisfaction to intentional behavior: testing a motivational sequence in two behavioral contexts. Pers Soc Psychol Bull. 2006; 32: 131-48.

26. Palmeira A, Teixeira P, Silva M, Markland D. Confirmatory Factor Analysis of the BREQ-2-Portuguese Version. Paper presented at the 12th European Congress of Sport Psychology, Halkidiki, Greece; 2007. 
27. Mullan E, Markland D, Ingledew DK. A graded conceptualisation of selfdetermination in the regulation of exercise behaviour: Development of a measure using confirmatory factor analytic procedures. Pers Ind Diff. 1997; 23: 745-752.

28. Markland D, Tobin V. A Modification to the Behavioural Regulation in Exercise Questionnaire to Include an Assessment of Amotivation, J Sport Exerc Psychol. 2004; 26: 191-196.

29. Koestner R, Otis N, Powers T a, Pelletier L, Gagnon H. Autonomous motivation, controlled motivation, and goal progress. J Pers. 2008; 76: 1201-30.

30. Ryan RM, Connell JP. Perceived locus of causality and internalization:Examining reasons for acting in two domains. J Pers Soc Psychol. 1989; 57: 749-761.

31. Silva MN, Markland D, Vieira PN, Coutinho SR, Carraça EV, Palmeira AL, et al. Helping overweight women become more active: Need support and motivational regulations for different forms of physical activity. Psychol Sport Exerc. 2010; 11: 591-601.

32. Silva MN, Markland EV, Carraça PN, Vieira SR, Coutinho CS, Minderico CS. et al. Exercise Autonomous Motivation Predicts 3-yr Weight Loss in Women. Med Sci Sports Exerc. 2011; 728-737.

33. Palmeira AL. Análise Factorial Confirmatória da Escala da Experiência Subjectiva com o Exercício - Versão Portuguesa. $7^{\circ}$ Congresso Nacional de Educação Física, Braga, 2006.

34. Mcauley E, Courneya KS. The Subjective Exercise Experiences Scale (SEES): Development and Preliminary Validation. Education. 1994; 163-177.

35. Blanchard CM, Rodger WM, Wilson PM, Bell GJ. Does equating total volume of work between two different exercise conditions matter when examining exercise-induced feeling states? Res Quart Exerc Sport. 2004; 75. 209-15.

36. Galinha I, Ribeiro J. Contribuição para o estudo da versão portuguesa da Positive and Negative Affect Schedule (PANAS): I Abordagem teórica ao conceito de afecto. Análise Psicol. 2005; 23.

37. Crawford JR, Henry JD. The positive and negative affect schedule (PANAS): construct validity, measurement properties and normative data in a large non-clinical sample. Br J Clin Psychol. 2004; 43: 245-65.

38. Watson D, Clark LA, Tellegen A. Development and validation of brief measures of positive and negative affect: The PANAS Scales. J Pers Soc Psychol. 1988; 47: 1063-1070.

39. Gray EK, Watson D. Assessing positive and negative affect via self-report. In J. A. Coan \& J. J. B. Allen (Eds.). Handbook of emotion elicitation and assessment (pp. 171-183). New York: Oxford University Press; 2007.

40. Borg GAV. Psychophysical bases of perceived exertion. Medicine and Science in Sports and Exercise. 1982; 14: 377-381.

41. Russell WD, Newton M. Short-term psychological effects of interactive video game technology exercise on mood and attention. Ed Tech Soc. 2008; 11: 294-308.

42. Baron RM, Kenny DA. The moderator-mediator variable distinction in social psychological research: Conceptual, strategic, and statistical considerations. J Pers Soc Psychol. 1986; 51: 1173-1182.

43. Bollen KA, Stine R. Direct and indirect effects: classical and bootstrap estimates of variability. Soc Method. 1990; 20: 115-140.
44. MacKinnon DP, Lockwood CM, Williams J. Confidence limits for the indirect effect: distribution of the product and resampling methods. Multi Behav Res. 2004; 39: 99-128.

45. Preacher KJ, Hayes AF. Asymptotic and resampling strategies for assessing and comparing indirect effects in multiple mediator models. Behav Res Met. 2008; 40: 879-891.

46. Preacher KJ. Introduction to Mediation, Moderation, and Conditional Process Analysis: A Regression-Based Approach. New York: Guilford Press; 2013.

47. McDonough MH, Crocker PRE. Testing self-determined motivation as a mediator of the relationship between psychological needs and affective and behavioral outcomes. J Sport Exerc Psychol. 2007; 29: 645-63.

48. Edmunds J, Ntoumanis N, Duda JL. Psychological needs and the prediction of exercise-related cognitions and affect among an ethnically diverse cohort of adult women. Inter J Sport Exerc. 2010; 8: 446-463

49. Moreno-Murcia J a, Martínez-Galindo C, Moreno-Pérez V, Marcos PJ, Borges F. Confirmation of the Basic Psychological Needs in Exercise Scale (BPNES) with a sample of people who do healthy exercise. J Sports Sci Med. 2012; 11: 141-146.

50. Assor A, Vansteenkiste M, Kaplan A. Identified versus introjected approach and introjected avoidance motivations in school and in sports: The limited benefits of self-worth strivings. J Ed Psychol: 2009; 101: 482-497.

51. Ekkekakis P, Parfitt G, Petruzzello SJ. The effect of intensity on the pleasure or displeasure people feel when they exercise: Decennial update and progress towards a tripartite rationale for exercise intensity prescription. Sports Med. 2011; 4: 641-671.

52. Garber CE, Blissmer B, Deschenes MR, Franklim BA, Lamonte MJ, Lee IM, et al. Quantity and quality of exercise for developing and maintaining cardiorespiratory, musculoskeletal, and neuromotor fitness in apparently healthy adults: Guidance for prescribing exercise. Med Sci Sports Exerc. 2011; 43: 1334-59.

53. Bartholomew KJ, Ntoumanis N, Ryan RM, Thøgersen-Ntoumani C. Psychological need thwarting in the sport context: assessing the darker side of athletic experience. J Sport Exerc Psychol. 2011; 33: 75-102.

54. Vansteenkiste M, Ryan RM. On psychological growth and vulnerability: Basic psychological need satisfaction and need frustration as a unifying principle. J Psychoth Integ. 2013; 23: 263-280.

\section{Corresponding autor}

Diogo S. Teixeira, PhD

Universidade Lusófona de Humanidades e Tecnologias, Faculdade de Educação Física e Desporto, 1749-024, Lisboa, Portugal.

Email: diogo.sts.teixeira@gmail.com

Manuscript received on February 19, 2016

Manuscript accepted on August 01, 2016

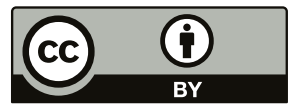

Motriz. The Journal of Physical Education. UNESP. Rio Claro, SP, Brazil - eISSN: 1980-6574 - under a license Creative Commons - Version 3.0 